\title{
LA INTEGRACIÓN ENERGÉTICA EN AMÉRICA DEL SUR: LA INICIATIVA DE PETROAMÉRICA
}

\author{
María del Rosío Vargas*
}

RESUMEN: El artículo intenta elaborar una semblanza del proceso de integración energética en América del Sur, de sus características más importantes así como de sus fallas. Con base en el análisis de estas últimas surge lo que parece ser un nuevo paradigma en materia de energéticos que cuestiona la aplicación del neoliberalismo a ultranza en la región. Dentro de este nuevo "consenso" está la idea de fortalecer en un contexto de mercado a las empresas energéticas cuando ello sea del interés público. Como parte de este proceso nace Petroamérica. De iniciativa venezolana Petroamérica busca la creación de una empresa multinacional que integre a las empresas energéticas públicas líderes, tales como PDVESA, ENARSA y Petrobras, al tiempo que la política petrolera internacional del presidente Hugo Chávez se dirige hacia Centro, Sudamérica y el Caribe en la forma de acuerdos de cooperación energética que muestran una estrategia geopolítica más amplia correspondiente al proyecto bolivariano mismo.

PALABRAS CLAVE: Integración energética, Petroamérica, Estrategia energética de George W. Bush.

ABSTRAC: This article tries to outline the energy integration process in South America, its main features and flaws. From this analysis arises what seems to be a new paradigm for the energetic issue that questions the implementation of full-fledged neoliberalism in the region. Within this unusual new "consensus" comes up the idea of the strengthening, in a market context, the energetic companies when that a public interest exists. As part of this process, from Venezuela sprung up Petroamérica, which pursues the creation of a transnational company that integrates top energy public companies, such as PDVESA, ENARSA, and Petrobras, while the President Hugo Chavez's international petroleum policy is heading toward Central and South America and the Caribbean as energetic cooperation agreements; that suggests a wider geopolitical strategy regarding Bolivar's project itself.

KEY WORDS: Energy integration, Petroamérica, George W. Bush's energy strategy.

* Centro de Investigaciones sobre América del Norte, UNAM (rvargas@servidor. unam.mx). 


\section{INTRODUCCIÓN}

El objetivo del presente artículo es analizar la iniciativa venezolana denominada Petroamérica en el contexto de la integración energética de Latinoamérica. Si bien Petroamérica, y ahora Petrosur, es una iniciativa propia del ámbito energético, su contenido político y estratégico parece ser de mayor alcance $\mathrm{y}$, en todo caso, podría considerarse como parte de un proceso de integración regional más amplio, que busca dar una respuesta anticipada al reforzamiento de la estrategia geopolítica hemisférica de Washington en contra de los regímenes contrarios al neoliberalismo en América Latina.

Numerosos son los factores que pueden considerarse relevantes desde el punto de vista de los energéticos en América Latina. De acuerdo con Samir Amin, la administración Bush trabaja duro por los recursos naturales del planeta para hacer frente a sus requerimientos de consumo. La carrera por las materias primas se ha reanudado con toda su virulencia, ${ }^{1}$ ya que es probable que los recursos se vuelvan más escasos cada día y no sólo en virtud de su uso dispendioso en las economías occidentales, sino por el desarrollo industrial de la periferia. La lucha por el control de los recursos estratégicos se da en un contexto de contienda hegemónica frente a sus adversarios: Europa, Japón, China e India, entre los más importantes. En el nivel mundial, Estados Unidos tiene una enorme ventaja sobre Europa y Japón, no sólo por tener el poder militar, sino porque estos últimos adolecen de la abundancia de dichos recursos. Se perfila, entonces, un conflicto potencial en las relaciones de los centros industrializados con las naciones en vías de desarrollo, en un contexto de complicidad y competencia entre los socios imperialistas por los recursos del Sur.

La importancia de la región radica en que cuatro de los principales abastecedores del mercado de Estados Unidos están en el Hemisferio

1 Amin Samir, "U. S. Imperialism, Europe and the Middle East", Monthly Review, vol. 56, núm.6, noviembre, 2004, p. 22. 
Occidental. Su potencial estratégico resulta innegable en vista de que tan sólo Brasil, Venezuela y Argentina suman en conjunto $11.5 \%$ de las reservas mundiales. Lejos del potencial del Medio Oriente pero nada desdeñable bajo una estrategia que como la estadounidense busca diversificar fuentes de aprovisionamiento y está dispuesta a explotar cualquier prospecto, aun cuando su producción no sea muy importante. Además Estados Unidos ya importa el doble de las fuentes localizadas en el Hemisferio Occidental que de los productores del Medio Oriente. ${ }^{2}$ Desde los años noventa América Latina empieza a sobrepasar al Medio Oriente como fuente de aprovisionamiento del mercado estadounidense. Algunos de los abastecedores principales de este mercado se encuentran en dicho hemisferio, por lo que la seguridad hemisférica es un asunto de permanente monitoreo para Estados Unidos. En materia de energía, ésta toma forma en la Iniciativa Energética Hemisférica ${ }^{3}$ que hace de la energía una de las prioridades no sólo de la política comercial, sino también de su política exterior. En este sentido la integración va encaminada a aumentar la oferta energética, como contribuir a fortalecer la seguridad energética de Estados Unidos a partir de suavizar o eliminar las barreras existentes para procurarse un acceso adecuado, confiable y rentable a los recursos energéticos de la región. Dicha integración se concibe bajo la forma de acuerdos de regionalización energética derivados del TLCAN (Tratado de Libre Comercio de América del Norte, como sería el ALCA (Área de Libre Comercio de las Américas) y el Plan Puebla Panamá.

Otro aspecto de esta iniciativa son las inversiones. La importancia de América Latina también radica en ser un mercado y un destino atractivo para las inversiones de las corporaciones energéticas de las nacio-

2 De hecho Estados Unidos importa el doble de crudo de las fuentes localizadas en el Hemisferio Occidental que del Medio Oriente. Energy Information Administration, Department of Energy, AER Historical Database; DOE/EIA. (Fecha de consulta septiembre de 2003).

3 Esta Iniciativa surge a partir de la Cumbre de las Américas celebrada en Miami en diciembre de 1994, bajo el argumento de la creciente necesidad de los países del Hemisferio de enfrentar un mercado de alta competitividad en la región. 
nes industrializadas, que buscan hacer negocios en materia de gas natural, electricidad, petróleo, así como en la misma integración física en la forma de ductos, redes eléctricas, buquetanques, etcétera.

\section{LA INTEGRACIÓN ENERGÉTICA DEL GAS NATURAL Y LA ELECTRICIDAD}

En los últimos años se ha profundizado la integración energética en el Cono Sur, sobre todo en materia de gas y electricidad. Esto se evidencia en el nivel alcanzado en las interconexiones físicas entre los países. Dichas interconexiones realizadas para el transporte de hidrocarburos y electricidad fueron, hasta inicios de la década pasada, primordialmente desarrollados por esfuerzos conjuntos de los gobiernos de los países, mediante una participación importante de sus empresas nacionales con el fin de asegurar los suministros de energía. Además de la necesidad de superar los desequilibrios entre oferta y demanda de energía en la región, uno de los factores que ha propiciado este proceso de integración ha tenido como propósito solventar los altos costos en infraestructura, a través de intentar un uso más eficiente, una mayor disponibilidad y un mejor acceso a los recursos naturales y financieros. Desde entonces, los actores privados han tenido un lugar principal en la creación de empresas gaseras, eléctricas, de nacionalidad estadounidense, canadiense y europea, quienes vienen desempeñando un papel principal en todas las formas que asume el proceso de integración energética. Ejemplos de lo anterior son las siguientes obras: el gasoducto Argentina-Chile; los proyectos de hidroelectricidad de Venezuela a Brasil; el campo de Camisea en Perú (véase mapa 1); ${ }^{4}$ el gas Boliviano; y en Centroamérica las compañías que exploran soluciones para proveer electricidad entre países.

${ }^{4}$ El campo de Camisea fue descubierto por la empresa Shell en 1984 y cuenta con un potencial en reservas del orden de 13 mil billones de pies cúbicos de gas natural y de 660 millones de barriles en líquidos. 


\section{Mapa 1. PROYECTO CAMISEA}

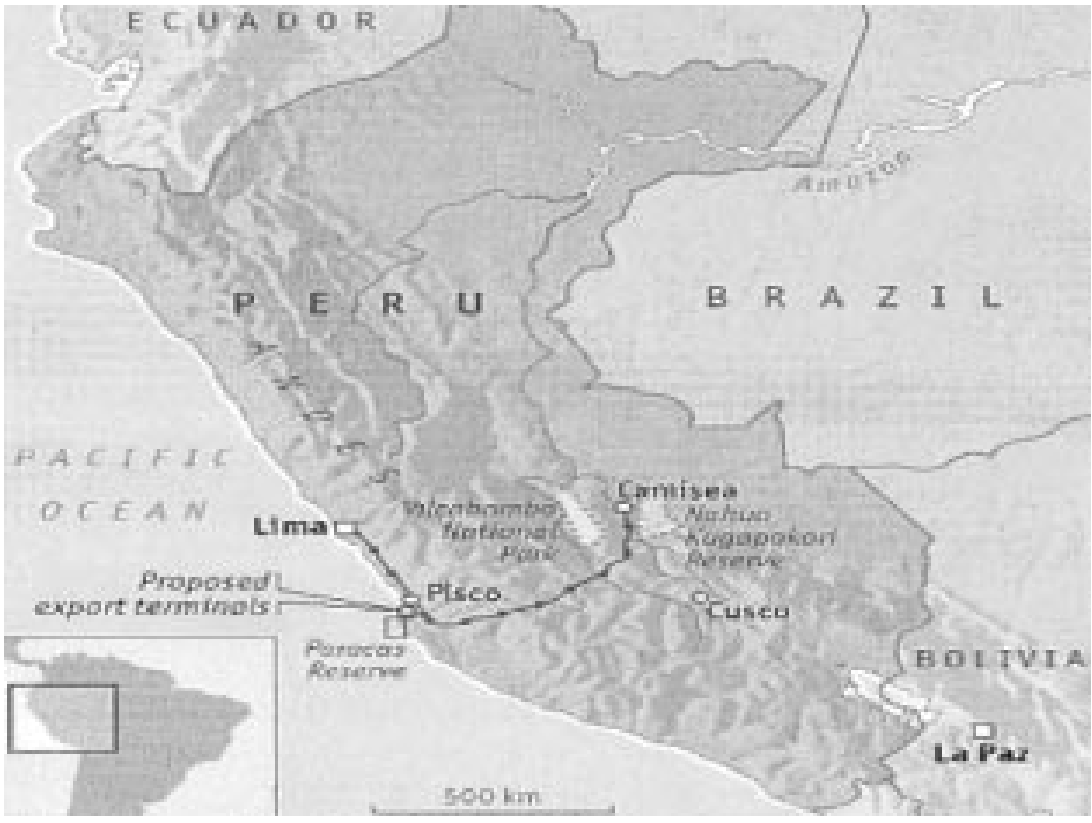

FUENTE: "Gas for Peru vs green imperialism", The Economist. En http:www.economist. com/displayStory.cfm?storyid=1978816. (Fecha de consulta 7 de agosto, 2003).

Las obras ya realizadas han constituido proyectos de largo aliento tal como el gasoducto Bolivia-Argentina, cuyo suministro no ha sido interrumpido desde su puesta en marcha hace 25 años. Otra de sus características es que este proceso de integración se ha dado a gran velocidad. De existir una única conexión entre países como la de Bolivia-Argentina, se realizaron cinco interconexiones de gas entre Argentina y Chile en menos de 6 años, dos conexiones con Brasil, una desde Argentina, otra desde Bolivia y, otra conexión más, entre Argentina y Uruguay. A este escenario se agregan líneas de transporte de electricidad de alta tensión de exportación que tienen su origen en la hidroelectricidad o el gas y oleoductos para exportación. Hay, sin embargo, muchos más proyectos de interconexión (véase mapa 2). 


\section{Mapa 2. RED DE GASODUCTOS EN SUDAMÉRICA 2002}

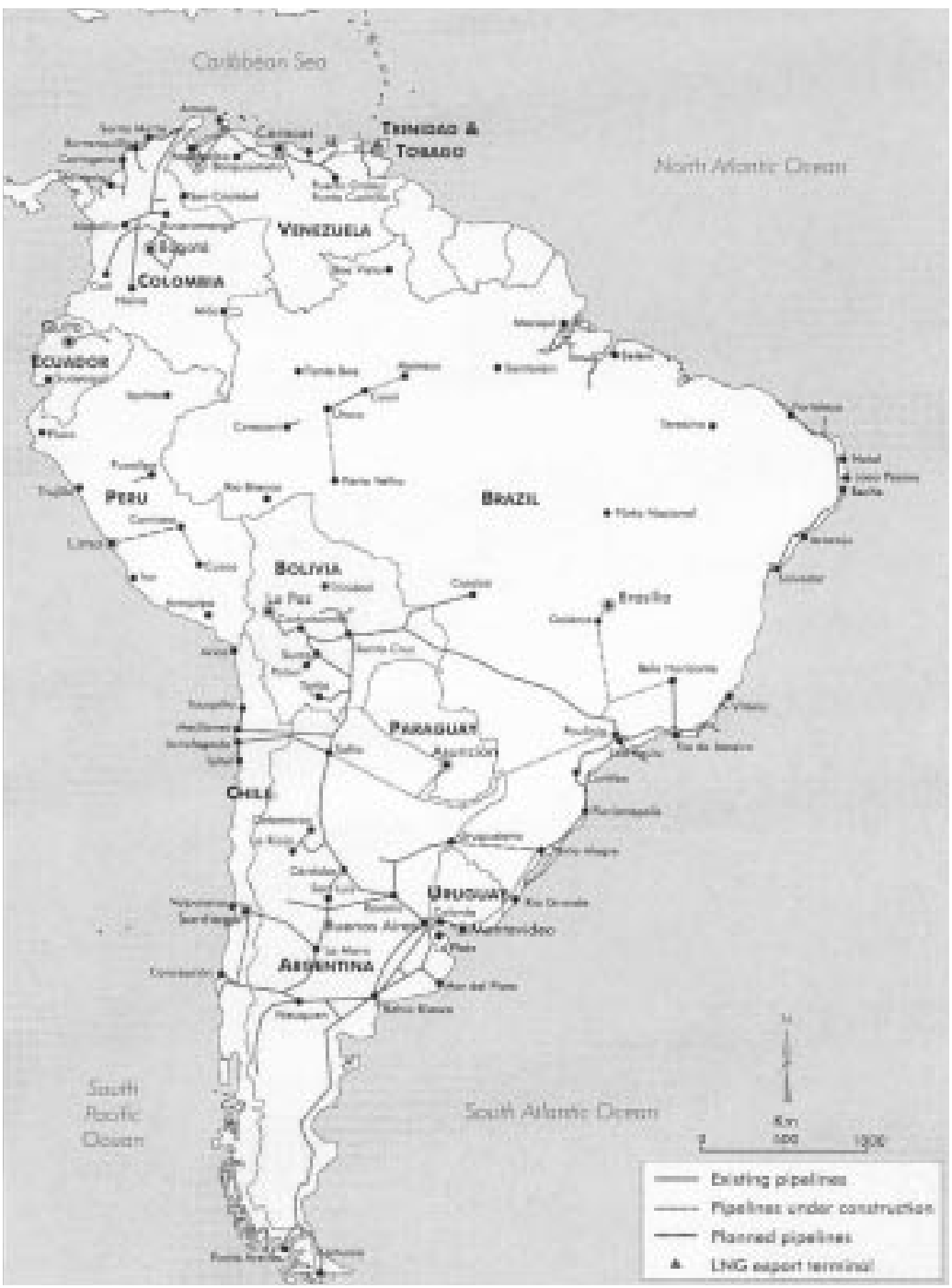

FUENTE: "South American Gas-Daringto Tap the Bounty, 2003", Agencia Internacional de Energía. En http:www.iea.org/dbtw-wpd/bookshop/add.aspx?id=61. (Fecha de consulta 7 de agosto, 2003). 
Insertos en la globalización y como parte de la orientación al libre mercado, el Hemisferio Occidental (a través del Tratado de Libre Comercio de América del Norte-TLCAN y de la integración de facto en América del Sur) ha orientado las políticas para construir y ampliar los mercados energéticos o " hacer el mundo más seguro para la inversión en energía”. En los años noventa estos objetivos han sido abanderados tanto por Estados Unidos como por las grandes potencias a fin de abrir espacios para sus inversiones en países en donde tenía preeminencia la inversión pública. Dan cuenta de ello: el capítulo 11 del TLCAN; los Acuerdos bilaterales entre Estados Unidos y Argentina, Bolivia y Ecuador; docenas de Acuerdos Bilaterales de Inversión (BIT) entre América Latina y "países exportadores de capital"; numerosos BIT entre países de América Latina; así como protocolos de inversión en el MERCOSUR. ${ }^{5}$

A la par que se proporciona el marco legal para la seguridad de la inversión extranjera en el sector, se elabora el marco jurídico que permita honrar las obligaciones contractuales, particularmente las que conciernen al Estado, la repatriación de ganancias, en tanto se comprueba un retroceso al ceder soberanía en favor de los tribunales internacionales de arbitraje.

A fin de lograr un marco jurídico institucional hemisférico en el cual se cobije este proceso de integración, Estados Unidos, desde hace

${ }^{5}$ Un BIT o Bilateral Investment Treaties ( por sus siglas en Inglés ) es un instrumento de la legislación internacional que provee a los inversionistas cierta protección respecto de sus inversiones en un país extranjero, y en la mayor parte de los casos un derecho a buscar una reparación contra acciones gubernamentales que, ellos consideran, les causa una pérdida. Esta reparación está disponible en la forma de arbitraje internacional contra el Estado huésped, con frecuencia bajo los auspicios del International Center for the Settlement of Investments Disputes (ICID), que es un organismo del Banco Mundial. Entre otras especificaciones, los BIT's establecen un esquema semiautónomo de regulación para la inversión extranjera. Básicamente, proveen derechos a los inversionistas y obligaciones para los estados, incorporan mecanismos para la resolución de disputas entre el Estado y los inversionistas, determinan la aplicabilidad de la ley y proveen reconocimiento y ejecución de la indemnización. Los mecanismos de resolución de disputas permiten a los inversionistas extranjeros suscribir una disputa a un procedimiento de arbitraje internacional, en el caso de que el inversionista se considere perjudicado por alguna medida adoptada por el país anfitrión. 
tiempo, ha diseñado la iniciativa del Acuerdo de Libre Comercio para las Américas o ALCA. Su objetivo último: quitar toda legislación previa en las naciones para hacer una regulación continental que proteja a las corporaciones transnacionales. Se pretende, a través del mismo, lograr la total interconexión energética desde Venezuela hasta Estados Unidos facilitando a las empresas eléctricas transnacionales invertir en proyectos de gas, ya que se prevé será el principal insumo para generar la energía en próxima década. Junto con el Plan Puebla Panamá, el ALCA vincularía los gasoductos locales al mercado eléctrico regional.

Si bien la integración ha mostrado sus bondades, la manera en que se ha hecho ha suscitado numerosos cuestionamientos a la luz de sus resultados. En particular me refiero a las privatizaciones de los activos del Estado a la par que el advenimiento de la inversión privada extranjera en activos nuevos y otrora considerados inversión pública por las características de los bienes en cuestión. En los últimos dos años (desde el 2003) se pueden encontrar sendos cuestionamientos a la forma en que se ha dado dicho proceso.

La venta de los activos energéticos no ha cumplido el propósito de solucionar el faltante fiscal:

1. El monopolio de los recursos energéticos en manos privadas no ha dado solución a la prestación y cobertura de los servicios para los sectores rurales.

2. No se ha cumplido con el aumento en la eficiencia y modernización del sector.

3. No ha mejorado la calidad de los servicios, particularmente en electricidad.

4. Se han encarecido los servicios en particular para los usuarios residenciales.

5. El debilitamiento de las empresas estatales dejó cesantes.

6. No se ha potenciado suficientemente los proyectos de las renovables.

7. En la región hay países que exportan energía a pesar de que no satisfacen su demanda. Estos son: Argentina, Colombia, Venezuela, Paraguay. 
8. Pese a que América Latina tiene una enorme disponibilidad de energía convencional, la integración de los mercados no ha significado el aprovechamiento cabal de estas potencialidades. Así, vastos sectores no tienen aún acceso a energía.

9. La competencia que se invoca al diversificar los actores de la oferta, no ha traído la eficiencia esperada, pues los fuertes monopolios privados de la región no lo permiten.

10. Las privatizaciones no han solucionado ni la deuda ni el déficit, más bien han debilitado el papel social del Estado y agudizado el problema de acceso y cobertura. Las privatizaciones adicionan un nuevo pasivo social y ambiental que el Estado está en dificultades para asumir.

11. El argumento de que la eficiencia privada es la salida a la ineficiencia pública es un sofisma que ha servido para subvalorar los activos energéticos de los estados en la región.

12. El paradigma economicista que había venido prevaleciendo en la orientación de los créditos valoraba como indicador macroeconómico el volumen de consumo de energía, lo que va en contra de las políticas de ahorro y uso eficiente y tampoco ha sido garantía para el mejoramiento de la economía local, ni de las subregiones.

13. Las instituciones energéticas nacionales son débiles para cumplir su papel regulador y de árbitro, ${ }^{6}$ lo cual ha movido la balanza a favor de los intereses y la orientación de las empresas privadas cuyo leit motiv es la ganancia que privilegia un horizonte de corto plazo.

A la par que hay fuerzas que pugnan por el mercado, existen cuestionamientos en torno a si la privatización radical ha sido la mejor solución al problema del manejo ineficiente de las empresas públicas y a su falta de recursos financieros. El establecimiento de los modelos neoliberales a ultranza ha devenido en problemas como subinversiones

${ }^{6}$ Gonzalo Castaño y Everardo Vélez, "La política del BID en el sector energético en América Latina", CENSAT Agua Viva Energy Paper, Bogotá, Colombia, marzo, 2000. 
y/o falta de capacidad excedentaria y descapitalización gradual de las empresas así como la pérdida del control de la renta petrolera.

Un problema para Estados Unidos, en relación con América Latina, ha sido la falta de consenso en las reformas energéticas en la mayor parte de los países de la región. ${ }^{7}$ En tanto desde el punto de vista del interés estadounidense no hay consenso para poner en marcha las reformas energéticas en los países del sur en América Latina, se podría decir que está surgiendo una nueva noción en el sentido de que los mercados son más eficientes sólo hasta el punto en donde los gobiernos los manejen en función del interés público. ${ }^{8}$ Allí donde hay un potencial amplio para la participación estatal, en términos de las economías de escala o el tipo de infraestructura requerida, las privatizaciones no garantizan por sí mismas la eficiencia. Las experiencias sugieren que la competencia en el sector así como también las privatizaciones de activos deberían reconsiderarse cuando la empresa estatal da muestras de eficiencia productiva.

\section{El SURGimiento De Petroamérica}

En este contexto surge Petroamérica. Estrategia sudamericana de iniciativa venezolana lidereada por el presidente Hugo Chávez, Petroamérica apela al espíritu Bolivariano. ${ }^{9}$ Se inserta en un proyecto de integración

7 Pierre Noël, "The United States and Latin American Oil. A case study in Normative International Economic Policy", presentación en la conferencia "Energía, reformas institucionales y desarrollo en América Latina", México, 6-7, noviembre, 2003.

8 Ibid., p. 4.

9 La primera pregunta es ¿por qué Venezuela? Sus posibilidades de liderazgo radican en su potencial petrolero. Venezuela tiene reservas probadas del orden de los 78 mil millones de barriles, excluyendo el petróleo extrapesado y el bitumen. Esto le permite niveles de producción del orden de 2.5 a 2.6 millones de B/D. Venezuela tiene cuatro de las cuencas sedimentarias más importantes como son: Maracaibo, Falcón, Apure y Oriental. El país es uno de los proveedores más importantes del mercado estadounidense en el que ocupa el $4^{\circ}$ sitio. Pese a su estrategia de diversificar mercados y socios comerciales considera que su principal mercado sigue siendo Estados Unidos. El 
económica, ${ }^{10}$ política y energética más amplia ${ }^{11}$ que intenta ser una alternativa al ALCA. Frente a éste, Chávez ha propuesto la Alternativa Bolivariana para las Américas (ALBA) que se intenta conducir bajo la lógica del humanismo y la solidaridad que caracteriza al proyecto Bolivariano. La creación del ALBA es, entonces, otra de las importantes tareas en este nuevo estadio. ${ }^{12}$ Apuesta al poder de negociación que da la unión, así como a la semejanza cultural de los países que la integrarían. En el nivel regional el ALBA está viendo culminar sus aspiraciones en la reciente conformación de la Comunidad Sudamericana de naciones que apuntan a la fusión del MERCOSUR y el Pacto Andino, lo cual hará de la región uno de los bloques regionales más importantes en el nivel mundial. ${ }^{13}$

gobierno de Venezuela ha abierto mucho de su sector de hidrocarburos a la inversión extranjera, promoviendo inversiones multimillonarias en la producción de crudos pesados, en la reactivación de campos así como en inversiones en algunas inversiones conjuntas (joint ventures) en materia de petroquímica. Casi $60 \%$ de las compañías extranjeras representan 14 diferentes países participantes en uno o más aspectos del sector petrolero venezolano. La compañía Nacional venezolana PDVESA ha firmado 33 contratos de operación con compañías extranjeras para pozos marginales en tres rodas de licitación. La nueva legislación que tiene que ver con gas natural y petroquímicos está abriendo el sector. Sin embargo, una nueva ley de competencia nacional, ha desalentado a los inversionistas a quienes se les había prometido precios fijados por el mercado.

10 Debe destacarse la importancia del MERCOSuR por sus objetivos políticos, sociales y económicos. Éste ha desempeñado un papel en el proceso de involucrar la recuperación y defensa de la democracia; la creación de una zona de paz a través de la defensa y uso pacífico de tecnología nuclear, así como por su involucramiento en la creación gradual de un mercado común.

11 En efecto, la política energética venezolana supone privilegiar los procesos de integración energética regional y subregional en América Latina y el Caribe. Dentro de esta última está, precisamente, la conformación de Petroamérica con el objetivo de integrar a las empresas estatales de América Latina y el Caribe para que inviertan conjuntamente en exploración, explotación y comercialización de petróleo y gas natural. Véase, óleo y gas natural. Véase, Organización Latinoamericana de Energía. Informe Energético de América Latina y el Caribe-2003, Quito, Ecuador, OLADE, octubre, 2004, p. 93.

12 Marta Harnecker, "After the Referéndum. Venezuela Faces New Challenges", Monthly Review, vol. 56, núm. 6, noviembre, 2004, p. 46.

13 Los mandatarios de Argentina, Ecuador, Bolivia, Brasil, Colombia, Chile, Guyana, Paraguay, Perú, Surinam, Uruguay y Venezuela firmaron la Declaración de Cuzco 
De acuerdo con el ministro de Energía y Minas de Venezuela, Rafael Ramírez: "juntos tendremos mayor poder y fuerza de negociación. Nos identifican culturas semejantes, el idioma, historia y problemas comunes, pero para ello es vital concensar acciones tecnológicas y comerciales para abaratar la energía en nuestros países" ${ }^{14} \mathrm{El}$ proyecto estratégico de Chávez parte de la idea de que estados que no tienen soberanía energética, tampoco pueden pretender la soberanía plena. Por tanto, la soberanía energética se vuelve un derrotero a alcanzar.

Petroamérica podría considerarse también como una reacción frente al Acuerdo de Libre Comercio para las Américas (ALCA), como parte de la Iniciativa Hemisférica y al control que han venido tomando las empresas transnacionales en el sector y en todos los países del Cono Sur. Más aún en virtud de que la globalización y el proyecto neoliberal han generado la idea de que es abierta la explotación de los recursos naturales a los intereses privados, existe el temor de los venezolanos de que las negociaciones del ALCA pudieran significar desventajas para su economía, sobre todo en materia petrolera. En el caso de que los países consumidores propusieran aplicar la tesis de que los hidrocarburos son un producto de la naturaleza que debe pertenecer a toda la humanidad, la integración podría implicar una amenaza, ya que se podría imponer la idea del libre acceso a la explotación del petróleo sin pagar renta alguna al Estado. De aplicarse este régimen petrolero los intereses de Venezuela, como país petrolero, se verían seriamente amenazados. ${ }^{15}$

Los venezolanos consideran que no es suficiente el control de los recursos a boca de pozo, (como lo está haciendo el presidente de Bolivia) sin la garantía y control pleno de toda la cadena de producción, fuentes, precios y distribución. También sugieren que el sector energé-

que da origen a un proyecto de integración para Sudamérica, cuyos alcances están aún por definirse. Véase, La Jornada, 10 de diciembre, 2004, p. 25.

14 Miguel Lora, "Petroamérica, la estrategia suramericana para recuperar su soberanía energética". En http:www.rebelio.org. 8 de junio, 2004.

15 Katiuska Hernández, "Advierte el viceministro de industria el ALCA puede ser una amenaza para el mercado petrolero", El Nacional, 23 de septiembre, 2002. 
tico debe ser visto como estratégico y no únicamente comercial. Su objetivo es, entonces, las empresas públicas nacionales, su integración con fines de exploración, desarrollo, refinación, transporte, almacenamiento, comercio y cooperación tecnológica. Es decir, toda la cadena productiva. La premisa básica es que sean compañías estatales que respeten las decisiones soberanas y el marco jurídico de cada país, al tiempo que atienden a toda la cadena productiva en el negocio de la energía.

Como antecedente de Petroamérica se puede mencionar que en noviembre de 1995, Petrobras (la compañía estatal Brasileña) y PDVSA firmaron una carta de intención, a través de la cual se establecían proyectos que incluirían la construcción de una refinería de 100000 B/D en Brasil para procesar petróleo venezolano, para luego cubrir actividades tanto corriente arriba como corriente abajo. ${ }^{16}$ Petrobras tiene la intención de invertir 1100 millones en Venezuela entre 2005 y 2009. Así también va a perforar en el 2005, numerosos pozos en Venezuela y a construir dos plantas de tratamiento.

Desde hace cuatro años que Venezuela impulsa Petroamérica a través de la iniciativa de unión de las petroleras estatales Petrobras, Petróleos de Venezuela (PDVSA) y Petroecuador.

Con este último y en la reunión de jefes de Estado de América del Sur en Guayaquil, Ecuador, el presidente de Venezuela Hugo Chávez propuso la creación de Petroamérica apelando a las bondades de una integración Bolivariana que buscaría la unión "concreta de riquezas y recursos". Entre los países latinoamericanos fueron congregados los mandatarios de Ecuador, Brasil, Colombia, Perú y Bolivia con la idea de formar esta empresa multiestatal petrolera, gasífera y energética, ${ }^{17}$ así como integrar a las naciones del subcontinente para fortalecer su posición en el mercado petrolero internacional.

Entre algunas de las propuestas de cómo podría operar Petroamérica está la forma de joint venture entre PDVESA y Petrobras bajo el esquema

16 URL: http://www.Venezuelactual.com/noticiasdetalles.asp?noticode $=6563$.

17 "La creación de Petroamérica". En http://bolivia.indymedia.org:8081/es/2002/08/

238.shtml. 20 de junio, 2003. 
$50 / 50 \%{ }^{18}$ a fin de avanzar en el derrotero principal que es el de una empresa transnacional que podría fusionar a varias estatales. Entre sus proyectos está la adquisición de una refinería en el Caribe para el procesamiento de crudos pesados venezolanos, así como la venta de gasolinas con la marca PDV en el mercado de Brasil.

En 2002, Venezuela y Brasil firmaron el primer acuerdo de cooperación para la exploración y explotación conjunta de gas natural y petróleo. El acuerdo incluye la construcción de una refinería valorada en 300 millones de dólares en Belem do Para, territorio brasileño, misma que será operada por Petrobras y PDVSA. Así también se prevén actividades de exploración y producción conjunta de petróleo y gas natural.

Venezuela también firmó con Ecuador un acuerdo energético binacional en el que PDVSA se compromete a brindar apoyo para modernizar la estructura técnica, administrativa y operativa de Ecuador. En 2003, los dos países acordaron en Quito la conformación de la "Unidad Hidrocarburífera Regional" y oficializaron el compromiso de crear Petroamérica. La propuesta era que PDVSA y Petroecuador operarían conjuntamente el sector gas, a través de contratos intergubernamentales, así como intervendrían en el comercio de gas licuado, gasolina, asfaltos y bases para la fabricación de lubricantes.

Con el gobierno Argentino dicha iniciativa se ha llevado adelante como parte del acuerdo de cooperación energética de mediano plazo que integra a PDVSA a Petrobras y que incorporaría a la empresa argentina, aún no nata, ENARSA. ${ }^{19}$ Venezuela participará en esta última con inversiones y asesoramiento técnico. La creación de ENARSA, por parte del gobierno de Néstor Kischner, dará un giro de 180 grados a las priva-

18 Carlos Chávez, "Petroamérica se concretiza en julio", El Universal de Caracas, 15 de mayo, 1997. En http://www.el-universal.com/1997/05/15/15201A.shtml. 20 de junio, 2003.

19 La propuesta, ya aprobada por el Congreso, es una compañía energética que permita al gobierno resolver la crisis energética por la que ha atravesado la sociedad argentina. El retorno de apagones y racionamiento masivo ha demostrado que la privatización de la industria energética en la década pasada no fue la panacea que se esperaba.Con 
tizaciones del sector energético al constituir esta empresa, de capital estatal, en un intento de incidir en un mercado doméstico totalmente controlado y manipulado por el sector privado. Como parte de los avances en la integración se puede mencionar la reciente apertura de una oficina de Venezuela en suelo argentino. Así también entre las acciones encaminadas a la cooperación se puede señalar que el primero vendió combustóleo y gasóleo a Argentina en el momento de su crisis energética. Además, astilleros de Argentina reparan y construyen los buques cisterna que necesita PDVSA. En vista de que Venezuela recién se sumó al MERCOSUR se ha empezado a hablar ya de Petrosur. La misma ENARSA está siendo constituida bajo la perspectiva integradora de Petrosur. Argentina se ha dado a la tarea de organizar la reunión que dará vida a Petroamérica. Durante la misma se pretende delinear la estrategia común.

Con Bolivia se está conformando una estrategia semejante a la que se ha llevado a cabo con Argentina, debido a la idea de refundar Yacimientos Petrolíferos Fiscales Bolivianos (YPFB). ${ }^{20}$ Con la firma de un acuerdo de cooperación Venezuela se comprometió a asesorar, técnicamente, a Bolivia bajo la gestión del actual presidente Carlos Mesa. En pleno trámite de la nueva ley de hidrocarburos el debate se mueve entre el extremo "nacionalizador" apoyado por Chávez en sintonía con Evo Morales del MAS y el de "transnacional" del presidente Carlos Mesa que defiende los contratos vigentes que tienen una duración de más de 35 años, aunque con nuevos gravámenes que llegarían a 50\%, a manera de regalías. Bolivia, convertida en potencia energética, sigue descubriendo nuevas reservas de gas, como el yacimiento del Departamento de Chuquisaca, superior a los pozos de Tarija. Entretanto Chile, en vísperas incluso de una crisis energética, sigue negándose a renegociar el Tratado de 1904, o alguna fórmula compensatoria que le permita a sus vecinos andinos "volver a ver el mar".

ENARSA el gobierno de Kischner espera garantizar un manejo honesto por parte del sector privado al tiempo que ésta cubra sus compromisos de inversión.

20 URL: http://www.bolivia.com/noticias/AutoNoticias/DetalleNoticias21701.asp. 
Otro aspecto del proyecto de Petroamérica son los convenios con los países del Caribe y Centroamérica que, además de significar un apoyo económico sustantivo ante el alza de los precios del petróleo, busca atender las necesidades energéticas de los vecinos al propiciar la integración. Resulta, sin embargo, innegable su contenido político en virtud de la filosofía política que viene mostrando la administración del presidente venezolano. A principios del mes de julio (10 y 12) de 2004, Venezuela tuvo una reunión con los países caribeños con los cuales suscribió un convenio preliminar de cooperación para refinar crudo y convertirlo en productos derivados a menores costos para la región. Esto a través de enviar crudo venezolano a la refinería de Trinidad y Tobago con destino al Caribe. ${ }^{21}$ Petrocaribe supone la revisión y modernización del Acuerdo Energético de Caracas firmado en $2000 .^{22}$

Con sus vecinos centroamericanos y caribeños Venezuela sostiene, junto con México, el Pacto de San José. Con Trinidad y Tobago Venezuela tiene interés en acuerdos de cooperación, intercambio y negocios en trabajo coordinado con Petrocaribe. Con Santo Domingo y República Dominicana se piensa una alianza regional que tendría como eje al petróleo.

Como parte de una alianza estratégica más amplia en fechas recientes (15 de diciembre de 2004) el presidente Chávez y el presidente Fidel Castro de Cuba han suscrito una serie de acuerdos que no tienen parangón. En lo que concierne a la cuestión energética el arreglo fija un precio piso para el petróleo venezolano que importa la Isla, abre de par en par las puertas al capital y a las exportaciones de Venezuela. Desde el año 2000 y con acuerdo, Venezuela vende a Cuba 53 mil barriles diarios de petróleo y derivados, equivalente a cerca de un tercio del consumo de la Isla. Para el anterior rigen tarifas de mercado pero se aplica un mecanismo de financiamiento mixto de corto y largo plazo que mejora mientras

21 "Venezuela tras integración energética con el Caribe". En URL http://www.mv.gov.ve/ noticias/index.php?act $=\mathrm{ST} \& \mathrm{f}=3 \& \mathrm{t}=6642$.

22 "PDVESA se asociará con países del Caribe para crear Petrocaribe". En URL http:// www.petroleumworld.com. 12 de agosto, 2004. 
más alto es el precio. Así también se aceptó que las inversiones del Estado venezolano en Cuba mantengan hasta $100 \%$ de su propiedad contra la norma prevaleciente para las inversiones mixtas en la Isla. Se prevé que este tipo de arreglos podrían aplicarse a proyectos como la modernización de la refinería de Cienfuegos y a la construcción de una termoeléctrica a base de carbón. Los acuerdos para el resto de la economía también son sumamente atractivos y pueden ser entendidos como parte de la alianza defensiva estratégica que ambas naciones erigen frente a la administración de W. Bush en rechazo a su propuesta integradora o ALCA. ${ }^{23}$

Alí Rodríguez, presidente de PDVSA en gira por Sudamérica, propuso a Paraguay y Uruguay venderles petróleo a "precios especiales" con el compromiso de comprarles otros bienes. ${ }^{24}$ En Paraguay, Chávez suscribió un acuerdo de cooperación energética por el cual Venezuela se compromete al suministro de crudo, productos refinados y Gas LP por la cantidad de hasta $18 \mathrm{mil} 600 \mathrm{~B} / \mathrm{D} .{ }^{25}$ Entró, asimismo, en negociaciones con la empresa Petropar que comprará petróleo y derivados a precios internacionales, pero con facilidades de financiamiento. Al parecer Uruguay buscará una fórmula semejante una vez que asuma el poder Tabaré Vázquez.

Pese a diferencias políticas con Colombia, a través de sus presidente Álvaro Uribe, el 10 de noviembre de 2004, Colombia acogió la iniciativa del presidente Chávez de impulsar los estudios necesarios para proceder con la expansión de la capacidad de refinación de ambos, para lo cual se conformarían cuadros técnicos entre PDVSA y ECOPETROL para analizar oportunidades y proponer acciones. ${ }^{26}$ Destacaron la idea de establecer alianzas estratégicas para el aprovechamiento del gas del campo Gi-

23 Gerardo Arreola, "Firman Cuba y Venezuela un abanico de acuerdos sin paralelo", La Jornada, 16 de diciembre, 2004, p. 27.

24 A Panamá se le hace una oferta similar.

25 Radio Nacional de Venezuela. En http://www.rnv.gov.ve/noticias/index.php?s=009 bf07c508b24a7f702cdebdbn6c. $1^{\circ}$ de diciembre, 2004.

26 http://www.visionvenezolana.com/ASP/ContDoc.asp?ND=86D2. $1^{\circ}$ de diciembre, 2004. 
braltar, ubicado en Colombia, cerca de Colombo-venezolana. En esta línea han pactado la construcción de un gasoducto binacional por lo que Colombia no quedaría excluida de este plan integracionista. Dicho gasoducto servirá primero para llevar gas a Venezuela y después para sacar el venezolano hasta el Pacífico. Sin embargo, el conflicto interno de Colombia y el grado de polarización política, sumada a la creciente dependencia de la ayuda militar de Estados Unidos, duplicada en efectivos, tiende a aislarla del resto de Latinoamérica. Su estrategia es atraer inversión extranjera en condiciones de privilegio que en opinión de algunos, poco rentará a la nación.

La iniciativa de Petroamérica no ha estado libre de dificultades, sobre todo en lo que concierne a la posible coordinación de políticas energéticas. A falta de la suficiente estructura institucional adecuada a la integración, han surgido propuestas para una Secretaría de Energía del MERCOSUR a fin de que reconsidere roles en cuanto al papel del Estado y del sector privado. ${ }^{27}$ En la XXVI reunión del MERCOSUR, que tuvo lugar el pasado 7 y 8 de julio de 2004, Argentina y Venezuela tuvieron una reunión bilateral en la cual acordaron poner en marcha dicha integración a través de Petrosur. ${ }^{28}$ Asimismo, representantes de Argentina, Bolivia, Brasil y Venezuela firmaron una declaración de apoyo a la integración durante la XXXV Asamblea de ministros de la OLADE (Organización Latinoamericana de Energía). Además Brasil y Venezuela suscribieron un amplio acuerdo de cooperación energética y minera. El comunicado oficial expresa que los gobiernos de Argentina, Bolivia, Brasil y Venezuela convinieron en dar pasos para la iniciativa de Petrosur y Enersur, apoyando el proyecto integracionista impulsado por Venezuela. Así Petroamérica, Petrosur, Enersur y Petrocaribe son parte de la misma iniciativa con diferentes denominaciones según el área geográfica comprometida, pero corresponden a la iniciativa venezolana y al deseo de la región de incorporarse a la misma.

27 OGEL, Special Feature: Energy, Institutional Reformas and Development in Latin America, vol. 2, núm. 3, julio, 2004, p. 3.

28 "Petrosur es ya una realidad". En URL http://www.alia2.net/article1397.html. 
Con todo lo anterior, es claro que Venezuela confirma su posición de líder y de magnate petrolero de la región. Si bien la iniciativa del presidente Chávez se inscribe en el plano de la energía resulta innegable el contenido geopolítico de sus acciones, tanto en la región como en ámbitos distintos al Cono Sur. Ejemplo de lo anterior son las acciones defensivas y armamentistas (la compra a la Federación Rusa de 40 helicópteros) así como del claro liderazgo en los campos de la diplomacia y el comercio energético. Así, ha propuesto que los astilleros argentinos sean los que construyan los "banqueros" de la flota propia para transportar el petróleo; ha abierto oficinas de PDVSA en Buenos Aires y ha lanzado la propuesta de hacer una "Alianza", extensiva a Brasil. Como ya hemos señalado Argentina ha revertido la política privatizadora de Menem al aprobar el Congreso la creación de la empresa estatal ENARSA al tiempo que da muestras claras de acoger la membresía de Petroamérica o Petrosur.

\section{LA REACCIÓN DE WASHINGTON}

Pese a que desde el 9 de noviembre de 2001 hubo un cambio muy claro en las prioridades de la política exterior en donde tanto la comunidad internacional como América Latina son "víctimas de la guerra contra el terrorismo", la región había permanecido en un lugar secundario en el orden de prioridades del Departamento de Estado. Hoy día (2004) no sólo es claro que permanece en la agenda del Pentágono y otros grupos de poder, sino que parece registrarse un proceso de militarización en la zona. Hay un número de efectivos entrenados del orden de los $22 \mathrm{mil}$ 850 hombres, en una expansión de este tipo de asistencia a las fuerzas armadas de la región, justificada con base en la lucha contra el terrorismo y el narcotráfico y la lucha contrainsurgente. Detrás de la creciente militarización en América Latina estaría el control de recursos estratégicos como el agua, el petróleo, el gas y otros recursos naturales. Junto a estos recursos: el interés de los mercados y el acceso a sus empresas. 
Estos objetivos, como ya se señaló son parte de los proyectos de desarrollo como el ALCA el Plan Puebla Panamá PPP y al Plan Colombia que es el principal enclave de las operaciones militares de Estados Unidos. Sin embargo, por la vía de la negociación comercial el acceso a estos objetivos se ha complicado y todavía muchos gobiernos controlan su sector energético. Así, por ejemplo, Estados Unidos preveía la entrada en vigor del ALCA para principios de 2005, pero las negociaciones están congeladas. Mientras tanto el interés en fortalecer la integración desde el Sur crece. Esto se vio reflejado el 18 de octubre de 2004 en las resoluciones de los representantes permanentes y aprobadas por los cancilleres de las 12 naciones de la ALADI. Las resoluciones sientan las bases para relanzar el foro. El paso siguiente podría ser ya la unión política en América del Sur. ${ }^{29}$

La falta de concreción en los acuerdos de integración comercial abanderados por Washington, el giro hacia la izquierda o centro izquierda de los regímenes más importantes en el Cono Sur como Argentina, Brasil, Venezuela y ahora Uruguay, así como el éxito del presidente Chávez en el referéndum revocatorio que le da una total legitimidad a su mandato que no ha dudado en desafiar los designios de Washington, darían cuenta del aumento del escrutinio de Estados Unidos hacia la región. ${ }^{30}$ En Washington ya se perfila lo que parece ser la política hacia América Latina en el futuro inmediato. Varios personeros y especialistas vinculados a América Latina, y especialmente el grupo de los neocon-

29 Raúl Pierre, "Salto Integrador no exento de tropezones, Servicio informativo sobre el Mercado del Cono Sur". En http://www.merco-sur.net/analisis/analisis_041104_ 01.htm. $1^{\circ}$ de diciembre, 2004.

30 La visión desde los centros de poder respecto de la presidencia de Chávez, al igual que los enfoques teóricos que acompañan y justifican la expansión del capital transnacional en el mundo, ven con desprecio el populismo de Chávez y no dudan en oponerlo como un valor contrario a la democracia. Populismo, nacionalismo y el triunfo del referéndum revocatorio de Chávez son vistos con gran desdén por quienes comparten la animadversión estadounidense por el mandatario venezolano. Véase Gema Santamaría, "El trágico triunfo de Chávez o la democracia que nunca fue", en Foreign Affairs en español, vol. 4, núm. 4, 2004, pp. 70-79. 
servadores, han demandado al gobierno de Bush el diseño de una estrategia que confronte a los "regímenes agresivamente antiestadounidenses", por lo cual se espera que el presidente Bush no tarde en lanzar un ultimátum intentando una violenta desestabilización en contra de Cuba, Venezuela, Argentina, Brasil, Uruguay y las fuerzas sociales de Ecuador. Parte de la agenda neoconservadora incluye "adoptar estrategias apropiadas para contender [...] el surgimiento de un número de regímenes agresivamente antiestadounidenses en América Latina”. Especialmente el régimen de Fidel Castro, por su antigüedad, está en primer lugar de la lista. En segundo término el presidente Hugo Chávez a quien consideran se podría suplantar dada la existencia de petróleo en esa nación. Chávez se ha vuelto el blanco de los ataques tras sus recientes visitas de Estado a Rusia, Libia, España y sobre todo, la más reciente a finales de 2004, a Irán. Tras esta última se vincula a Chávez con el grupo Al Qaeda aduciendo un financiamiento por parte del primero a la organización. En una actitud de clara represalia al desempeño político del presidente Chávez, y en declaraciones de la nueva secretaria de Estado, Condoleezza Rice, Estados Unidos buscará la manera de reducir el consumo petrolero proveniente de Venezuela. También es posible que el Departamento de Estado vigile con mayor severidad a Citgo (empresa de propiedad venezolana en territorio estadounidense) con el pretexto de apoyar con su crudo al gobierno cubano. ${ }^{31}$ Venezuela por su parte tiene en la mira relocalizar activos de PDVSA de Europa y Estados Unidos para ubicarlos en el Cono Sur. Esto es aún un proyecto. En general, los neoconservadores se preocupan porque la tendencia en (América Latina) sigue un curso, según ellos, equivocado. Mientras tanto Castro y Chávez suman fuerzas para promover una agenda en la región. ${ }^{32}$

Si bien Bolivia no está dentro de los estados considerados hostiles a Washington, tampoco parece librarse de estar en la mira de la admi-

31 "The Economist, Condoleezza Rice y la política de Washington hacia la región", $L a$ Jornada, 30 de noviembre, 2004, p. 24.

32 Jim Cason y David Brook, "Cuba, Venezuela, Brasil, Argentina, Uruguay y Ecuador, en la mira de los neoconservadores", La Jornada, 6 de noviembre, 2004, p. 24. 
nistración Bush en virtud de lo controversial que ha resultado el debate en torno a la nueva ley de Hidrocarburos. ${ }^{33}$ Más que el mismo presidente de Bolivia, Carlos Mesa, quien parece ser objeto de la preocupación de la presidencia republicana es el líder social Evo Morales. El estigma y las agencias de seguridad están sobre él.

Ante este contexto, es claro que Petroamérica parece ser no sólo un proyecto energético, que corresponde a una tendencia de integración regional económica y política más amplia. Es, al igual que estas últimas, una estrategia de defensa y de soporte mutuo de los países que están cuestionando el neoliberalismo y reaccionando ante los debastadores resultados sobre sus economías y sociedades. Es una estrategia de defensa contra una doctrina de defensa preventiva que a través de mecanismos como la "cláusula democrática" busca deshacerse de líderes no afines a los intereses de Washington, como es claro con el caso cubano y venezolano. Petroamérica o Petrosur es por el momento la estrategia sudamericana que intentaría la integración de los estados en lo energético, con miras a formar una transnacional capaz de competir con las más importantes del mundo. En virtud de que el proceso de integración es un hecho, al igual que el innegable liderazgo de Chávez, es de esperarse que en poco tiempo Bolivarianismo y Monroismo entren en conflicto.

¿Cuáles podrían ser los posibles obstáculos a este proyecto? En primer término que a las potencias, en general y a Estados Unidos en particular, no les conviniera una asociación de esta naturaleza, sobre todo en lo que se refiere a los aún incipientes acuerdos entre PDVSA y Petrobras. Más decidido Kischner quien apoya la propuesta de integración, deja ver

33 Si bien Bolivia no está incluida en la lista de los neoconservadores hay indicios de que la embajada de Estados Unidos gesta un golpe contra el mandatario Carlos Mesa en momentos en que la Cámara de Diputados avanza en la aprobación de una nueva ley petrolera de corte estatista. Fuertes intereses transnacionales saldrían afectados ya que 27 petroleras de Europa, Asia y América controlan actualmente la riqueza boliviana de gas natural. Además de que muchos yacimientos petroleros importantes ya se encuentran en manos de empresas estadounidenses, La Jornada, 23 de noviembre, 2004, p. 23. 
que la conformación de ENARSA se armonizará con Petrosur. No obstante, es claro que dos países importantes México y Chile se mantienen al margen del proyecto integrador, por no decir que el primero hace las veces de Caballo de Troya a través de su papel en la iniciativa del ALCA, PPP y su conocido plegamiento a los lineamientos del "amigo Bush". Pero como arriba señalábamos hay ya claros signos de obstáculos mayores.

BiBLIOGRAFÍA*

The White House, The National Security Strategy of the United States of America, Washington, septiembre, 2002.

OLADE/CEPAL/GTZ, Interconexiones y perspectivas para el comercio de gas natural en América Latina y el Caribe 2000-2020, Buenos Aires, Argentina, 1999.

OLADE, Informe de la Organización Latinoamericana de Energía, 2002. PROYECTO OLADE/CEPAL/GTZ, Los mercados del gas natural en la comunidad Andina: desarrollo y perspectivas de integración, Ecuador, julio, 2001.

OLADE, Estudio para la integración del mercado del gas natural en América del Sur (informe final), enero, 2001.

OLADE, Incorporación del gas natural en la interconexión eléctrica en América Central, junio, 2001.

CEPAL/ECLAC, Resultados de la reestructuración de la industria del gas natural en Argentina, noviembre, 2002.

Sitio del MERCOSUR

http://mercosur.org.uy

Iniciativa para la integración de la infraestructura Regional Sudamericana http://www.iirsa.org

${ }^{*}$ Fuentes complementarias. 
Radio Nacional de Venezuela http://www.env.gov.ve

Ministerio de Relaciones Exteriores de la República Bolivariana de Venezuela

http://www.mre.gov.ve

Petrobras http://www. petrobras com.br

PDVSA http://www.pdvsa.com

Ecopetrol http://www.ecopetrol.gov

Enarsa http://www.iae.org.ar 